and thereby offer scientists attractive posts. Furthermore, most firms are wary of research workers with a university background and prefer, when recruiting scientists, to look for them in the major colleges such as the Polytechnique or the Centrale. And university lecturing, also suggested as an alternative solution for those excluded from the CNRS, has been completely transformed in recent years, with the result that a teaching background is insisted on for lecturers. It is not at all certain that the universities will find satisfactory recruits among the members of the CNRS who had chosen precisely this field in order to pursue their work without any teaching commitments. The only course for those affected by this measurewhich from now on must be repeated year after yearseems therefore to be to yield sooner or later to the temptations of the brain drain. The American "headhunters" indeed have been making conquests in France for some time, and young people in France are beginning to have a better knowledge of English than their elders.

\section{Money and Health}

THAт the "healthiest" countries (judged in terms of mortality) spend most on health services is one of the conclusions reached in the 1967 World Health Organization report, An International Study of Health Expenditure (price 12s.) covering 29 countries. The obj-ctives of this report were two-fold: to compile comparable information on cxpenditure on health services and on methods of financing such scrvices, and to develop a standardized framework for national health accounting that could be used as a routine aid to health planning in all countries.

Most of the figures in the report were drawn from questionnaires, and the countries covered were not, it is emphasized, necessarily representative of all countries in the world because of the difficulty of obtaining information from countries with lower standards of living. Estimates of health expenditure for each country are compared with gross national product and national income.

It seems that over the period of study Israel, Canada, and the United States spent the greatest proportion of national income on health services, while the proportion of Gross National Product devoted to health services varied from 2.5 per cent to $6 \cdot 3$ per cent in countries providing full information. Countries with relatively high standards of living tended to spend more on health expenditure than countries with a lower standard of living. As the latter countries have on the whole poorer health than richer countries, less was spent both absolutely and in relation to total resources where the need was greatest.

The report states that generally there is no evidence of correlation between health expenditure and the need for health services: rather, health expenditure is prosumably influenced to a large extent by the "felt needs" of governments. No country was found in which less than 25 per cent of the money spent on health services came from public funds and among the high-income countries those receiving heaviest government support were not those allocating most money to health expenditure.

Breaking down the capital expenditure on health services, with the exception of Pakistan and France,
18 countries allocated 88 per cent or more to personal health services. Furthermore, hospitals took more than 74 per cent of capital expenditure in all countries except Chile, Czechoslovakia and Yugoslavia. The United Kingdom was well down the list with only $76 \cdot 4$ per cent provided through hospitals compared with 99.7 per cent in Canada, although a spokesman at the Ministry of Health said that 14 hospitals had in fact been built in England and Wales since 1948.

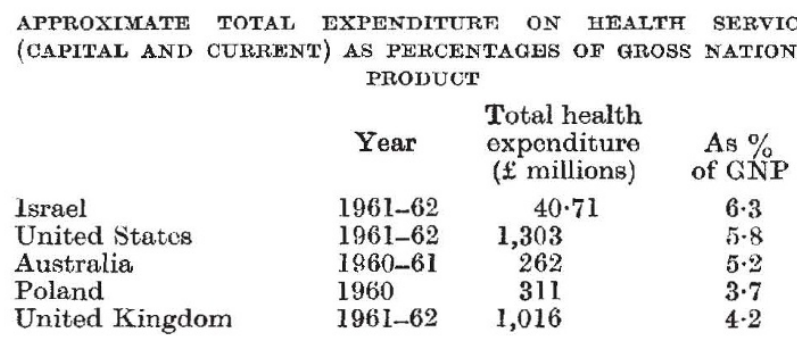

Looking to the future, until cost-benefit analysis and other techniques become applicable to the selection of targets for health programmes, the report suggests that it is desirable that the costs of health services should be consistent with a chosen long-term plan, and that the plan should be firmly based on economic realities.

\section{Developing Oxford}

\section{from our Oxford Correspondent}

As Nature went to press, Congregation at Oxford was voting on a proposal for acquiring new sites in north and central Oxford, principally for the university's scientific and administrative institutions. The administration of the university has been conducted from various buildings in different parts of Oxford, the Registry being, for example, in the Clarendon Building in the centre, while the financial department is threequarters of a mile away in Wellington Square. In 1965 , it was proposed that the Registry should expand into the premises of the nearby Indian Institute, which would then be displaced if not dismembered. Much criticism was directed at this proposal and Bodley's librarian resigned on account of it. Now, because the university has bought a number of houses around Wellington Square and also because the Franks Commission recommended that the administrative buildings should be in one place, the Hebdomadal Council has decided to apply for planning permission to redevelop Wellington Square, and move all the administrative buildings into that area. But a new Indian Institute library is already being built on top of the new Bodleian. If, then, the new proposal is accepted, all but the ground floor of the Clarendon Building and the old Indian Institute will be empty.

The council has not yet put forward suggestions for using this extremely valuable area in the centre of Oxford, considering it "premature" until planning permission has been granted for the Wellington Square development. It is possible that Hertford College will take over some of the Indian Institute building, but part at least will continue to be used as a library. Similarly, it is suggested that the Taylorian Institute and Modern Languages Faculty will take up residence in one cormer of Wellington Square, leaving another large central area empty. Here again no decision has yet been made on how to use the space. 